\title{
Research Paper: The Effect of Selected Core Stability Exercises on Balance and Muscle Endurance in the Elderly Patients Undergoing Hemodialysis
}

\author{
Mehrdad Bastani ${ }^{1}$, Gholamali Ghasemi ${ }^{*}$, Morteza Sadeghi ${ }^{1}$, Amirreza Afshon ${ }^{2}$, Hossein Sadeghi $^{3}$
}

1. Department of Sport Injuries and Corrective Exercises, Faculty of Sport Sciences, University of Isfahan, Isfahan, Iran. 2. Department of Physiotherapy, School of Rehabilitation Sciences, Shiraz University of Medical Sciences, Shiraz, Iran. 3. Shahid Mohammad Montazeri Hospital, Isfahan University of Medical Sciences, Najafabad, Isfahan, Iran.

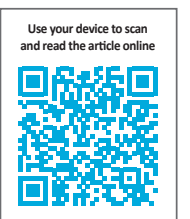

Crtati on: Bastani M, Ghasemi Gh, Sadeghi M, Afshon A, Sadeghi H. The Effect of Selected Core Stability Exercises on Balance and Muscle Endurance in the Elderly Patients Undergoing Hemodialysis. Physical Treatments. 2017; 7(2):89-96. http:// dx.doi.org/10.32598/ptj.7.2.89

http://dx.doi.org/10.32598/ptj.7.2.89

Article info:

Received: 11 Jan 2017

Accepted: 05 May 2017
Keywords:

Core stability exercises, Hemodialysis, Balance, Elderly people

\begin{abstract}
A B S T R A C T
Purpose: The elderly patients undergoing hemodialysis who developed end-stage renal failure are at higher risk for falling and its critical outcomes compared with their healthy counterparts due to of poor balance, reduced muscle endurance, and sedentary lifestyle. The current study aimed at evaluating the effect of selected core stability exercises on balance and muscle endurance in the elderly patients undergoing hemodialysis.
\end{abstract}

Methods: In the current quasi-experimental study, a total of 30 patients undergoing hemodialysis with the mean age of $62.24 \pm 6.51$ years, the mean hemodialysis duration of $29.4 \pm 18.44$ months, and the history of falling at least once during the last year were selected using the purposive convenience sampling method and then, the subjects were randomly allocated into 2 groups of intervention $(\mathrm{n}=15)$ and control $(\mathrm{n}=15)$. To assess the static balance, dynamic balance, and muscle endurance in the patients, the stork stand test, the timed Up and Go test (TUG), and the sit-to-stand-to-sit test for 60 seconds (STS-60) were used, respectively. The selected core stability exercises were performed for the intervention group in 6 weeks, three 45 -minute sessions per week. To analyze data, the repeated measures analysis of variance (RM ANOVA) with SPSS version 22 was used; $\mathrm{P}<0.05$ was considered the level of significance.

Results: Results of the current study indicated significant differences between the groups in terms of static balance, dynamic balance, and muscle endurance $(\mathrm{P}<0.001)$. In other words, the implemented exercises significantly affected the studied variables.

Conclusion: Based on the obtained results, the therapists can suggest the core stability exercises as a safe and functional strategy to improve balance and muscle endurance in patients undergoing hemodialysis, which may result in increased independence of action and reduced risk of falling due to loss of balance.

\footnotetext{
* Corresponding Author:

Gholamali Ghasemi, PhD

Address: Department of Sport Injuries and Corrective Exercises, Faculty of Sport Sciences, University of Isfahan, Isfahan, Iran.

Phone: +98 (937) 8841112

E-mail: gh.ghasemi@sprui.ac.ir
} 


\section{Introduction}

P

atients with end-stage renal failure usually suffer from a type of physical disability, which persuades them toward using alternative treatments in order to survive, which hemodialysis is one of the most common ones [1]. Based on the Iranian official statistics, the number of Iranian patients with incurable diseases is annually increased about $15 \%$ [2]. The increasing trend of hemodialytic cases in Iran is almost 3 times more than the global trend [3]. Along with elderly general population increase, the mean age of patients undergoing hemodialysis also increases [4], in such a way that about $70 \%$ of the patients are above 55 years [5].

The aging is associated with the risk of falling [6]. In the general community, 1 in 3 elderly above 65 years old and 1 in 2 elderly above 80 years old experience falling at least once a year by average; only $5 \%$ of such fallings cause serious damage [7]. The number of patients undergoing hemodialysis is increased by mean age increase, since degenerative nature of hemodialysis revealed the fact that such patients are at lower health status in physical, mental, emotional, and cognitive aspects, compared with healthy people [8]. Hemodialysis should be performed in horizontal position and the patient annually spends about 800 hours in such a position without any physical activity; hence, it is associated with adverse effects such as reduced physical endurance, muscle weakness, and strength loss [9]. The adverse effect of coil dialyzer on patients with chronic renal failure exposes them at the risk of falling 4 times higher than that of the general elderly population; also, pelvic fracture followed by falling doubles the rate of mortality among such patients, compared with the rate of general elderly population [10]. Identification and prevention of the common complications of such disabled patients, who are considered as the senior citizens, are of great importance in order to improve their quality of life.

The balance is of the most important indices of daily activities for elderly people [11]. Poor balance and physical readiness in the elderly is a multifactorial subject [12]. Since irreversible consequences such as falling caused by reduced balance threat the lives of elderly people [11], prevention of falling is the best treatment. Different studies indicated that along with age increase, strength and endurance of the muscles also reduced, which in turn results in reduced balance, elevated body swing, and consequently, increased risk of falling [11]. The nature of hemodialysis and sedentary lifestyle expose the patients under hemodialysis to a large spectrum of physical and physiological complications [13]. The elderly people undergoing hemodialysis in spite of challenging with the age-appropriate neurological, arterial, and vision disorders [14], should deal with motion neuropathy and skeletal muscle myopathy [13]. Therefore, it seems that peripheral neuropathy of organs predisposes patients undergoing hemodialysis to poor balance and falling more than any other factor; as it corrupts the process of transmitting massages from lower extremities to the Central Nervous System (CNS), which significantly influences the balance maintenance. In addition to sedentary lifestyle and long-time rest [9], such patients should adhere to the healthcare providers' recommendations to have lower physical activity in order to better maintain the graft and catheter installed on their hands or feet.

The aforementioned issues are the clear reasons for reduced movement, strength, and balance in patients undergoing hemodialysis, compared with the healthy people [9]. In patients who cannot manage transmitting the messages between their lower extremities and CNS, the muscle structure refunds the defect and maintains the balance [15]. The center of body is the center of gravity and the origin of body movements; hence, strengthening the muscles of this area significantly improves neuromuscular system function, endurance, and decreases displacement of body center of gravity out of base of support and consequently improves balance maintenance [16]. The effect of different exercises on the quality of physical performance in the elderly patients undergoing hemodialysis was reported in different studies. The researchers indicated that 4 weeks core stability exercises could improve the bases of support as well as physical functioning and independence of action in the elderly [11].

Bennet et al. (2012) indicated that the risk of falling decreased following the balance training included equilibrium control exercises in patients undergoing hemodialysis [17]. The core stability exercises on and off a Swiss ball, which has unstable and dynamic nature, significantly improves balance and performance and reduces the risk of falling in the elderly patients and can be involved in other programs for rehabilitation purposes $[16,18]$. Although some studies reported insignificant effect of core stability exercises on balance improvement in the elderly patients $[19,20]$, reduced physical activity in the elderly highlights the important role of such exercises [11, 16], the evident, which can be generalized to the population of the elderly undergoing hemodialysis.

Owing to 3 remarkable weaknesses of patients undergoing hemodialysis as lower ability to receive sensory 
messages in feet, reduced physical activity, and undeniable role of center of body in physical functioning, participation in core stability exercise programs although is very fruitful, it highly corresponds with particular physical and economic conditions of this group of elderly patients. However, lack of investigation on the effect of complementary exercise programs on the function of elderly patients undergoing hemodialysis and owing to the increased rate of falling in this group of the community, the study authors aimed at designing a study in order to evaluate the effect of selected core stability exercises on balance and muscle endurance in the elderly patients undergoing hemodialysis, based on their conditions and dynamicity requirements.

\section{Materials and Methods}

The current quasi-experimental study with pre-testpost-test-control group design aimed at evaluating the effect of 6 weeks selected core stability exercises on balance and muscle endurance in the elderly patients undergoing hemodialysis. The study population included all patients undergoing hemodialysis in the Dialysis Center of Shahid Mohammad Montazeri, Najafabad, Isfahan, Iran, during spring 2016. The purposive convenient sampling method was used to select sample size after approving the research project by the Research Council of the university; for this purpose, after obtaining the introduction letter from the Deputy Vice Chancellor (Research), the authors referred to the Dialysis Center of the hospital and after studying the medical records and interweaving the patients within consecutive days, the eligible patients were selected. The inclusion criteria were the age range 55-75 years, history of falling at least once during the last year due to balance loss and not dizziness, lack of physical disability, and lack of independence to rehabilitation aids.

The exclusion criteria were the use of rehabilitation aids, asthma, dizziness, frequent changes in general health conditions, and unwillingness to participate in the study. Before intervention, a demographic questionnaire (including age, gender, marital status, level of education, and the type of therapeutic support) plus medical history information (history of dialysis, frequency of dialysis per week, history of falling, and taking psychoactive and cardiovascular drugs) was completed for each subject via face-to-face interviewing and review of medical records and the final results were provided as a personal report for each subject. After evaluation of candidates in terms of the inclusion and exclusion criteria, 30 eligible subjects were selected and in a meeting, the objectives and stages of the study were explained to them, and they were asked to sign the informed consent form. Before intervention, the qualification of the subjects to take place in an exercise program was confirmed by a specialist. Then, the subjects were randomly allocated into 2 groups of intervention $(n=15)$ and control $(n=15)$. The subjects underwent dialysis three 4-hour sessions per week with at least 12 months of initiation of treatment.

The intervention group attended the selected core stability exercise sessions held by a physiotherapist for 6 weeks; the controls were recommended to continue their daily activities, while committing to their therapeutic regimens. Likewise, a nephrologist who was aware of the study objectives was assigned to prepare weekly reports of the subjects' health status and monitor them, while controlling the study conditions. The participants performed the exercises in a $20 \times 20 \mathrm{~m}$ ground hall covered with suitable sport mates and all the subjects were asked to wear proper cotton cloths at exercise sessions. They were also recommended to stop exercises as soon as they felt dizziness, headache, heartthrob, nausea, and any other inconveniences and immediately inform the attending nurse. The first sessions only included a short interval of slow breathing exercises, which were gradually increased in time and speed. The vital signs of the participants were checked every 15 minutes, and the first aid box as well as drinking water was also available in place. Necessary cares and recommendations were given to the participants, particularly the ones with diabetes. The static as well as dynamic balance, and muscle endurance of the participants were evaluated 48 hours before and 48 hours after the last session of intervention. Three subjects in the intervention (due to dizziness, absence, and withdrawal) and 2 subjects in the control groups (due to dependence on wheelchair and withdrawal) were excluded from the study.

To evaluate the static balance, the stork stand test was used. For this purpose, the subjects is asked to stand on their preferred (dominant) foot, while placing the hands in front of the chest and taking the non-dominant foot about $5 \mathrm{~cm}$ above the ground. The test is completed when the subject touches the ground with his non-dominant foot, the dominant foot is being displaced from the first position or twisted in any direction. The mean time of maintain balance based on the aforementioned conditions in 2 consecutive tests was considered as the patient's record; the maximum score was 120 seconds [21]. The validity (0.99) and reliability $(0.87)$ of the test was confirmed [22].

In addition, to evaluate the dynamic balance of the patients, the timed Up and Go test (TUG) was used [21]. 
Table 1. The selected core stability exercises

\begin{tabular}{|c|c|c|c|c|c|c|}
\hline \multicolumn{7}{|c|}{ The Core Stability Exercises for $\mathbf{3 0}$ Minutes } \\
\hline \multicolumn{2}{|c|}{ Warming-Up } & \multicolumn{2}{|l|}{10 Minute } & \multicolumn{3}{|c|}{ Walking, Stretching and Kinetic Exercises } \\
\hline \multirow{4}{*}{ 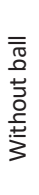 } & Item & Type of exercise & Week 1 & Week 2-3 & Week 4-6 & Week 6 \\
\hline & 1 & Bridging in supine position & $3 \times 8$ Seconds & $10 \times 3$ Seconds & $10 \times 3$ Seconds & $12 \times 3$ Seconds \\
\hline & 2 & Cycling in supine position & $3 \times 8$ Seconds & $10 \times 3$ Seconds & $10 \times 3$ Seconds & $12 \times 3$ Seconds \\
\hline & 3 & Half sit-ups & $3 \times 8$ Repeat & $10 \times 3$ Repeat & $10 \times 3$ Repeat & $12 \times 3$ Repeat \\
\hline \multirow{6}{*}{$\begin{array}{l}\overline{\bar{\pi}} \\
\text { 总 } \\
\text { 点 } \\
3\end{array}$} & 4 & Bridging on the ball & $3 \times 8$ Repeat & $10 \times 3$ Repeat & $10 \times 3$ Repeat & $12 \times 3$ Repeat \\
\hline & 5 & $\begin{array}{l}\text { Raising the legs up and holding the ball } \\
\text { between them }\end{array}$ & $8 \times 2$ Repeat & $10 \times 2$ Repeat & $10 \times 3$ Seconds & $12 \times 3$ Repeat \\
\hline & 6 & $\begin{array}{l}\text { Widening the trunk on the ball in prone } \\
\text { position }\end{array}$ & $8 \times 2$ Repeat & $10 \times 2$ Repeat & $10 \times 3$ Repeat & $12 \times 3$ Repeat \\
\hline & 7 & $\begin{array}{l}\text { Widening the trunk on the ball in supine } \\
\text { position }\end{array}$ & & $10 \times 2$ Repeat & $10 \times 2$ Repeat & $10 \times 3$ Repeat \\
\hline & 8 & Twisting the pelvis on ball & & & $10 \times 2$ Repeat & $10 \times 3$ Repeat \\
\hline & 9 & Pushing the ball up the wall & & & $10 \times 2$ Seconds & $10 \times 3$ Seconds \\
\hline
\end{tabular}

Cooling down

5 Minute

Walking and stretching exercises

PHYSICAL TREA MMENTS

The test has 3 stages: Stand up from the chair, walk a distance for 3 meters, turn and walk back to the chair. In the current study, the time of the test was considered as a dependent variable and measured using a chronometer. Also, an armless chair was used in the current study and the subject was asked to place his feet shoulder-width apart. While the subject announced his readiness, by saying Go the chronometer was started and stopped as soon as the back of the subject touched the chair in returning. The score of the patient was the mean score of 2 attempts recorded in seconds. The reliability of TUG is $99 \%$ [23].

The muscle endurance of lower extremities, particularly legs, was measured using the sit-to-stand-to-sit test for 60 seconds (STS-60). The test was performed using a $44.5 \mathrm{~cm}$ wooden chair placed in front of a wall. To measure the muscle endurance, the subject was asked to consecutively stand up from and sit-down on the chair with safety and full caution, while after each time he should stand up straight with each hand holding the other arm. The number of sit-to-stand turns in a 60 minute interval was recorded for each patient and if he could not continue, the test was stopped. The STS-60 has good validity and reliability [24].

The core stability exercises were also used in the current study. The selected exercises used in the current study were obtained from those used in a study by Seo, with little modifications (Table 1) [21]. The protocol recommended in the current study was adjusted to physical activity of the study subjects as well as their health status and hemodialysis requirements. Since the program was implemented in patients undergoing hemodialysis for the first time, a preliminary study prior to the intervention was conducted in order to ensure the compatibility of the exercises with patients' conditions and prevention of unintended consequences. The preliminary study included warming-up (10 minute), core stability exercises (30 minutes), cooling-down (5 minutes) for 6 weeks, each week 3 sessions on off-dialysis days [25]. Based on the physical conditions of the study participants, $75-\mathrm{cm}$ Swiss balls were used; the break time in the 3 first weeks of the intervention was more than that of the 3 last weeks.

Data were analyzed with SPSS version 23 using the repeated measures analysis of variance (RM ANOVA). The correction of sphericiy was applied in order to use RM ANOVA. $\mathrm{P}<0.05$ was considered as the level of significance.

\section{Results}

Demographic data of the study participants are shown in Table 2 . Accordingly, $12 \%$ of the subjects were selfemployed and $88 \%$ jobless, while $20 \%$ were illiterate and the educational level of $80 \%$ was under diploma. All subjects had experienced falling due to balance loss in their lower extremities at least ones in the last year. In addition, the study participants developed the end-stage renal failure due to diabetes (54\%), blood pressure (30\%), and other reasons such as lupus and polycystic kidney disease (16\%). No significant differences was observed between the groups in terms of demographic characteristics and medical history $(\mathrm{P}<0.05)$; hence, the both group were homogeneous prior to the intervention. 
Table 2. Demographic data of the study participants

\begin{tabular}{ccccc}
\hline Group & Number & Age $(\mathbf{y r})$ & Duration of Dialysis (mo) & Height (cm) \\
\hline Intervention & 15 & $62.58 \pm 6.77$ & $30.75 \pm 14.97$ & $171.08 \pm 4.07$ \\
Control & 15 & $61.92 \pm 6.52$ & $28.15 \pm 21.7$ & $172.15 \pm 4.48$ \\
\hline
\end{tabular}

Table 3. Results of descriptive data analysis and ANOVA for the studied variables

\begin{tabular}{|c|c|c|c|c|}
\hline Variable & Turn of the Test & Intervention Group (Mean \pm SD) & Control Group (Mean \pm SD) & Interaction \\
\hline \multirow{2}{*}{ Static balance (s) } & Pre-test & $2.68 \pm 2.30$ & $3.45 \pm 3.41$ & \multirow{2}{*}{$\begin{array}{l}F=14.98 \\
P \leq 0.001\end{array}$} \\
\hline & Post-test & $2.32 \pm 2.32$ & $5.12 \pm 2.81$ & \\
\hline \multirow{2}{*}{ Dynamic balance (s) } & Pre-test & $16.15 \pm 5.67$ & $15.56 \pm 6.09$ & \multirow{2}{*}{$\begin{array}{l}F=44.67 \\
P<0.001\end{array}$} \\
\hline & Post-test & $10.63 \pm 4.56$ & $16.85 \pm 5.35$ & \\
\hline \multirow{2}{*}{ Muscle endurance (sit-to-stand-to-sit) } & Pre-test & $14.83 \pm 6.10$ & $14.32 \pm 7.10$ & \multirow{2}{*}{$\begin{array}{l}F=31.40 \\
P<0.001\end{array}$} \\
\hline & Post-test & $21.50 \pm 7.61$ & $12.77 \pm 6.32$ & \\
\hline
\end{tabular}

Descriptive data analysis and ANOVA results for the study variables are shown in Table 3. The interaction is the most important component to the RM ANOVA; the RM ANOVA evaluated the differences between the groups. In other words, RM ANOVA compares the trend of changes (line slope) between the groups and indicates the superiority and possible influence of groups over each other. According to Table 3, all the 3 variables of static balance, dynamic balance, and physical functioning have significant interaction toward each other $(\mathrm{P}<0.05)$. In other words, changes in the intervention group were significantly higher than the control group and in the intervention group had more progression. Based on the Figures 1, 2 and 3, the slope gradient in the intervention group was higher than that of the control group, which indicates the improvement of static balance, dynamic balance, and muscle endurance in the intervention group subjects.

Based on Figures 1, 2 and 3, six weeks after the selected core stability exercises in the intervention group, the level of static balance improved from $2.68 \pm 2.60$ to $5.12 \pm 2.18$, dynamic balance from $16.15 \pm 5.67$ to $10.63 \pm 4.56$, and the muscle endurance from $14.8 \pm 6.10$ to $21.50 \pm 7.61$.

\section{Discussion}

Based on the results of the current study and comparing the pre-test and post-test results of the study subjects, it can be concluded that the selected core stability exercise program along with hemodialysis therapy can significantly improve the static balance, dynamic balance, and muscle endurance (the risk factors associated with falling) in the patients undergoing hemodialysis.

Results of the current study was in agreement with those of the most studies in the same field indicating the efficacy of non-pharmaceutical strategies such as walking, cycling along hemodialysis therapy, and the combined strength-balance exercises on the improvement of functioning and physical capacity of patients undergoing hemodialysis $[8,9,17]$. Although the aforementioned interventions were implemented along the hemodialysis therapy for more 3 months, significant results were obtained from the current study with a 6-week intervention implemented apart from the time of dialysis. The selection of core stability exercises in the current study was relied on high compliance with mental and physical status of the elderly people undergoing hemodialysis. There was no incompatibility between the core stability exercises, and disability or limited physical movement of the elderly people and they had no barrier to do the exercises. Likewise, results of the current study were in line with those of Petrofsky et al. (2005) as well as some other studies that used the core stability exercises as a kind of resistance exercises and reported the efficacy of the exercises on the improvement of static balance, dynamic balance, and strength, endurance, and performance of neuromuscular system in the study subjects $[11,26,27]$. Results of a study by Panjabi et al. (1992) on the effect of core stability exercises on dynamic bal- 


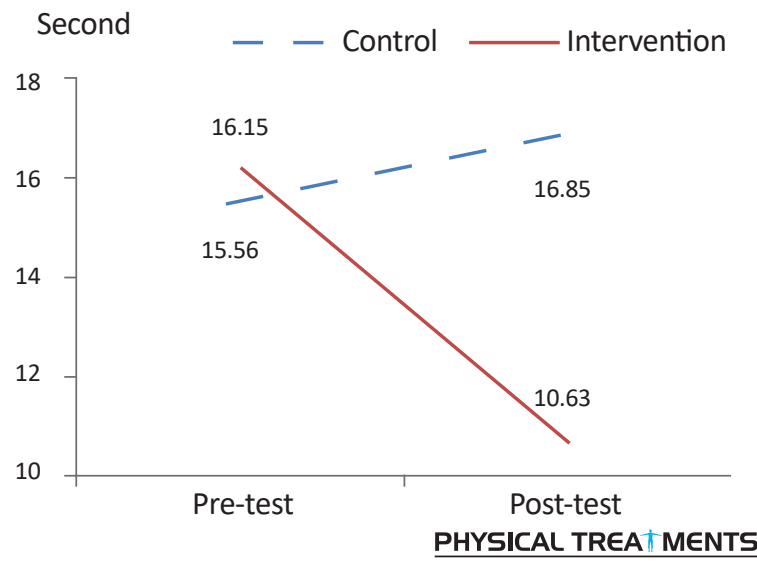

Figure 1. Static balance changes in the study groups

ance indicated that the contraction of core muscles before moving a limb can activate the predictive postural responses by CNS; hence, the core stability exercise program can improve the activity prediction and consequently, reduce the risk of imbalance, swinging the center of body, and falling in the patients [28].

Based on the results of a study by Doustan et al. (2010) there were different reasons for the efficacy of core stability resistance exercises on balance; in one hand, the resistance exercises increase the irritation of muscular mass, which in turn result in increased strength and endurance of muscles and on the other hand, such exercises increase strength and endurance of trunk and legs and can reduce the muscle co-contraction and improve body balance and stability. In addition, such exercises increase blood pressure in brain and CNS, which results in higher efficacy of cerebellum (the body balance control center) and pyramid cells to transmit the messages [29]. In the current study, a significant part of core stability exercises were performed using the Swiss balls; based on the results of different studies on the effect of exercises on

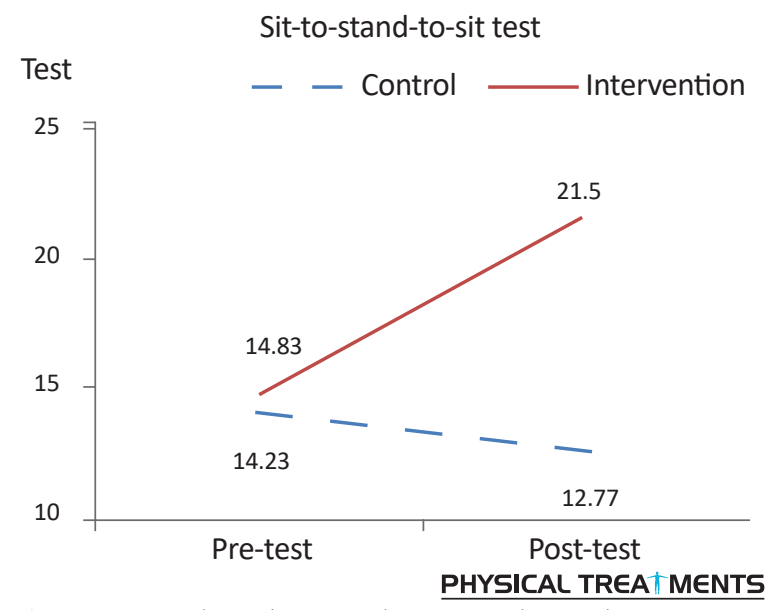

Figure 3. Muscle endurance changes in the study groups

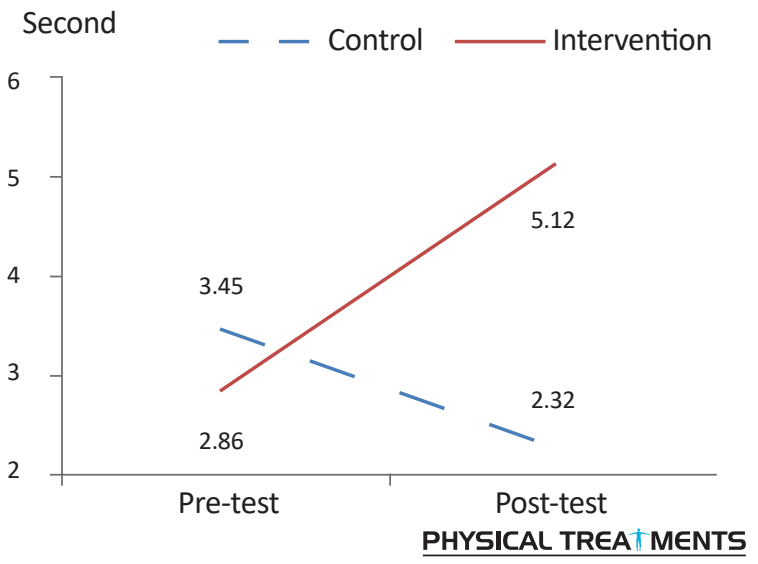

Figure 2. Dynamic balance changes in the study groups

Swiss ball, the patient can do a wide range of exercises recreationally by placing on a Swiss ball and trying consciously to maintain the balance during the core stability exercises. Also, such exercises can be a good activity to challenge the systems involving in body balance [27] Hence, the equilibrium control exercises by imposing overload on human sensory system (visual, vestibular, somatic sensation), and increasing muscle strength and range of motion in joints pave the way for balance improvement [30]. Results of a study by Casio et al. (2003) indicated that 5-week core stability exercise programs on Swiss ball or field have similar effects on the improvement of balance and body control [18]; the results were consistent with those of the current study. In agreement with the results of the current study, Golpayegani et al. (2009) reported that the core stability exercises on and off a Swill ball, due to the dynamic and instable nature of the Swiss ball, is effective on the balance improvement, physical functioning, and rate of falling in the elderly population and can be involved in the rehabilitation and treatment readiness programs [16]. In contrast, Carmeli et al. (2003) and Lewarchik et al. (2003) indicated that Swiss ball and the core stability exercises had no impact on the results of balance test $[19,20]$; the differences between the later studies results and those of the current study can be attributed to the demographic characteristics of the studied populations; the subjects of the study by Carmeli were the patients with mental retardation and Lewarchik enrolled the young and healthy football players, while the current study was conducted on the elderly males undergoing hemodialysis within the age range of 55-75 years and the history of falling; hence, there was a considerable differences between the studied populations in terms of cognitive level, physical readiness, and age range. To justify contradicted studies, the study by Golpayegani et al. indicated that following the core stability exercises, the balance was more improved in the 
elderly who were at higher risk for falling compared with their counterparts with lower risk of falling [16], the reason can be explained by the fact that the core stability exercises can facilitate neuromuscular transmission and in conclusion, the selected exercises were mostly useful for the ones with poor balance.

One of the objectives of the current study was the high rate of falling in the elderly patients undergoing hemodialysis that was not considered in any of the previous studies. The protocol of core stability exercises on and off Swiss ball along with the compliance with the physical and clinical conditions of such patients is capable of implementing at home without any help in order to increase the level of balance and strength, and totally reduce the risk of falling in the elderly patients undergoing hemodialysis. Such exercises are targeted to strengthen abdominal and lumbar muscles; the importance of doing such exercises by the elderly patients undergoing hemodialysis, who have reduced feet movement due to different neuropathic and myopathic complications, is twice more than that of their healthy counterparts. Owing to the usefulness of other exercise programs, using the protocols similar to the provided intervention is more effective in maintaining daily physical activity of such patients [26]. Of the limitations of the current study, monitoring of nutritional status and mental complications of the study subjects, and classification of the subjects based on the causes of chronic renal failure are highlighted, which is expected to be considered in further studies. Also, evaluation of the effect of such exercises on other factors and underlying symptoms associated with the performance of hemodialytic patients and comparing the results with those obtained from different non-pharmaceutical methods are recommended.

\section{Acknowledgements}

This paper was extracted from the first author's MSc. thesis in Department of Sport Injuries and Corrective Exercises, Faculty of Sport Sciences, University of Isfahan, Iran with registration code of IR.UI.REC.1396.017. We are very grateful to the hemodialysis patients, the officials of the Shahid Mohammad Montazeri Hospital and Ghamar-e Bani Hashem Charity Association who have been involved in the implementation of this project.

\section{Conflict of Interest}

The authors declared no conflicts of interest.

\section{References}

[1] Fauci B, Brounwald E, Kasper DL, Hauser SL, Longo DL, Jameson JL. Harrison's principles of internal medicine. Philadelphia: Mc Graw Hill; 2008.

[2] Baraz S, Mohammadi E, Broumand B. [The effect of selfcare educational program on decreasing the problems and improving the quality of life of dialysis patients (Persian)] Journal of Hayat. 2005; 11(2):51-62.

[3] Mozafari N, Mohammadi MA, Dadkhah B, Mahdavi A. Dialysis adequacy of haemodialytic patients in Ardabil dialysis (Persian)]. Journal of Ardabil University of Medical Sciences. 2002; 4(4):52-7.

[4] Collins AJ, Foley RN, Chavers B, Gilbertson D, Herzog C, Johansen K, et al. United States Renal Data System 2011 Annual Data Report: Atlas of chronic kidney disease \& end-stage renal disease in the United States. American Journal of Kidney Diseases2012; 59(1): 1-420. doi: 10.1053/j. ajkd.2011.11.015

[5] Gray NA, Grace BS, McDonald SP. Peritoneal dialysis in rural Australia. BMC Nephrology 2013; 14:278. doi: 10.1186/14712369-14-278

[6] Laessoe U, Hoeck HC, Simonsen O, Sinkjaer T, Voigt M. Fall risk in an active elderly population - Can it be assessed. Journal of Negative Results in BioMedicine. 2007; 6(1). doi: 10.1186/1477-5751-6-2

[7] Bogle Thorbahn LD, Newton RA. Use of the Berg Balance Test to Predict Falls in Elderly Persons. Physical Therapy. 1996; 76(6):576-83. doi: 10.1093/ptj/76.6.576

[8] Endo F, Asakawa Y, Usuda S, Yamamoto T. Effects of daily walking exercise on chronic hemodialysis outpatients. Journal of Physical Therapy Science. 1996; 8(1):1-4. doi: 10.1589/ jpts.8.1

[9] Chojak K, Smolenski O, Milkowski A, Pitrowski W. The effects of 6-month physical training conducted during hemodialysis in ESRD patients. Medical Rehabilitation. 2006; 10(2):25-41.

[10] Leinau L, Perazella MA. Fellows ' Forum: Hip fractures in end-stage renal disease patients: Incidence risk factors and prevention. Seminars in Dialysis. 2006; 19(1):75-9. doi: 10.1111/j.1525-139x.2006.00122a.x

[11] Petrofsky JS, Cuneo M, Dial R, Pawley AK, Hill J. Core strengthening and balance in the geriatric population. Journal of Applied Research in Clinical and Experimental Therapeutics. 2005; 5(3):423-33.

[12] Lopes K, Costa D, Santos L, Castro D, Bastone A. Prevalence of fear of falling in a population of elderly in the community and its correlation with mobility, dynamic balance, risk and history of falls. Brazilian Journal of Physical Therapy. 2009; 13(3):223-9. doi: 10.1590/s1413-35552009005000026

[13] Soangra R, Lockhart TE, Lach J, Abdel-Rahman EM. Effects of hemodialysis therapy on sit-to-walk characteristics in end stage renal disease patients. Ann Biomed Eng. 2013; 41(4):795-805. doi: 10.1007/s10439-012-0701-6.

[14] Clary S, Barnes C, Bemben D, Knehans A, Bemben M. Effects of ballates, step aerobics, and walking on balance in women aged 50-75 years. Journal of Sports Science \& Medicine. 2006; 5(3):390-9. 
[15] Mattacola CG, Livengood AL, DiMattia MA, Uhl TL. Dynamic trendelenburg: Single-leg-squat test for gluteus medius strength. Athletic Therapy Today. 2004; 9(1):24-5. doi: 10.1123/att.9.1.24

[16] Mahdavi S, Golpayegani M, Hesari A. [Effect of six weeks of core stability training program on fall incidence in women older adults (Persian)]. Iranian Journal of Ageing. 2009; 5(17):95-106.

[17] Bennett PN, Breugelmans L, Chan D, Calo M, Ockerby C. A combined strength and balance exercise program to decrease falls risk in dialysis patients: a feasibility study. Journal of Exercise Physiology. 2012; 15(4):26-39.

[18] Cosio-Lima LM, Reinolds KL, Winter C, Paolone V, Jones MT. Effects of physioball and conventional floor exercises on early phase adaptations in back and abdominal core stability and balance in women. Journal of Strength and Conditioning Research. 2003; 17(4):721-5. doi: 10.1519/00124278200311000-00016

[19] Lewarchik T, Bechtel ME, Bradley DM, Hughes CJ, Smith TD. The effects of a seven week core stabilization program on athletic performance in collegiate football players. Journal of Athletic Training. 2003; 38:80-81.

[20] Carmeli E, Bar Chad S, Lotan M, Merrick J, Coleman R. Five clinical tests to assess balance following ball exercises and treadmill training in adult persons with intellectual disability. The Journals of Gerontology Series A: Biological Sciences and Medical Sciences. 2003; 58(8):M767-72. doi: 10.1093/ gerona/58.8.m767

[21] Seo BD, Kim BJ, Singh K. The comparison of resistance and balance exercise on balance and falls efficacy in older females. European Geriatric Medicine. 2012; 3(5):312-6. doi: 10.1016/j.eurger.2011.12.002

[22] Khajavi D, Farokhi A, Jaberi Moghadam AA, Kazemnejad A. [The impact of a training intervention program on fallrelated psychological factors among male older adults in Arak (Persian)]. Iranian Journal of Ageing. 2014; 9(1):32-9.

[23] Fathi Rezaie Z, Aslankhani MA, Farsi AR, Abdoli B, Zamani SS. [A comparison of three functional tests of balance in identifying fallers from non-fallers in elderly people (Persian)]. Knowledge \& Health. 2010; 4(4):22-7.

[24] Segura Ortí E, Martínez Olmos FJ. Test-retest reliability and minimal detectable change scores for sit-to-stand-to-sit tests, the six-minute walk test, the one-leg heel-rise test, and handgrip strength in people undergoing hemodialysis. Physical Therapy. 2011; 91(8):1244-52. doi: 10.2522/ptj.20100141

[25] Gage MJ. The effects of abdominal training on postural control, lower extremity kinematics, kinetics, and muscle activation [PhD dissertation]. Provo: Brigham Young University; 2009.

[26] Panjabi MM. [The stabilizing system of the spine. Part I: Function, dysfunction, adaptation, and enhancement (Persian)]. Journal of spinal disorders. 1992; 5(4):383-9.

[27] Kazemi AA, Mahdavinejad R, Ghasemi Gh, Sadeghi M. [Effects of an 8-week exercise with Physioball on the correction of thoracic kyphosis, balance and quality of life in addicted men after quitting drugs (Persian)]. Journal of research in rehabilitation sciences. 2013; 9(2): 328-37.
[28] Dostan M, Aslankhani MA, Ebrahim Kh, Sifoorian M. [Effect of eight weeks stretch and resistance training on balance and reaction time in inactive elderly men (Persian)]. Journal of Motor Behavior and Psychology of Sport. 2010; 2(1):32334.

[29] Carpes FP, Reinehr FB, Mota CB. Effects of a program for trunk strength and stability on pain, low back and pelvis kinematics, and body balance: A pilot study. Journal of Bodywork and Movement Therapies. 2008; 12(1):22-30. Doi: 10.1016/j.jbmt.2007.05.001

[30] Toulotte C, Thevenon A, Watelain E, Fabre C. Identification of healthy elderly fallers and non-fallers by gait analysis under dual-task conditions. Clinical Rehabilitation. 2006; 20(3):269-76. doi: 10.1191/0269215506cr929oa 